\title{
Espaço Público e Criatividade Urbana A dinâmica dos lugares em três bairros culturais ${ }^{1}$
}

\section{Luís Balula*}

Resumo: A desterritorialização da esfera pública e as formações sociais emergentes nos "espaços públicos" virtuais da sociedade em rede têm vindo a concorrer para uma acentuada erosão da vida colectiva nos espaços públicos e lugares urbanos tradicionais. No entanto, a par desta nova cidade dos fluxos, determinadas áreas urbanas centrais distinguem-se enquanto espaços de referência para a cidade dos lugares. Este estudo - que pretende contribuir para a discussão da Cidade Criativa - analiza comparativamente as dinâmicas de três destes lugares urbanos, informalmente reconhecidos enquanto "bairros criativos", ou "bairros culturais": Bairro Alto em Lisboa; Vila Gracia em Barcelona; e Vila Madalena em São Paulo.

Na primeira parte do artigo expõem-se os pressupostos teóricos do estudo: uma abordagem ao tema da criatividade urbana a partir do binómio espaço público/esfera pública; o reconhecimento da importância de determinadas actividades económicas para a vitalidade dos espaços públicos; e a hipótese que a morfologia do espaço público - determinante da forma como as pessoas dele se apropriam - associada a uma grande concentração de espaços privados de uso público, contribui decisivamente para a criatividade e competitividade dos territórios urbanos. A segunda parte do artigo descreve os três estudos de caso, em que se analisam comparativamente as dinâmicas dos espaços públicos e dos espaços privados de uso público dos três bairros em termos da sua funcionalidade, acessibilidade, e morfologia; bem como a percepção de diversos agentes-chave locais das relações entre estes factores urbanísticos e a criatividade, vitalidade, e competitividade de cada bairro.

Esta análise permite identificar algumas das condições e oportunidades dos territórios urbanos tradicionais para atrair e fixar actores e actividades criativas. Por outro lado, permite igualmente examinar criticamente a possibilidade de desenvolvimento de novas áreas urbanas competitivas mas socialmente e culturalmente responsáveis.

Palavras-chave: Espaço público; Criatividade; Cidades criativas; Bairros culturais; Actividades económicas; Vitalidade urbana; Competitividade urbana; Bairro Alto, Vila Gracia, Vila Madalena.

\section{Espaço público e esfera pública}

When making the city more attractive in the knowledge economy the local authorities can invest in the creativity of their population. But a word of warning: creative cities cannot be constructed from the ground up. The roots of creativity, in fact, always lie in the existing, historically developed urban environment. (Hospers, 2003: 143)

No centro da pólis grega, a ágora representa o espaço público por excelência. Cercada por edifícios públicos e local de mercados e feiras, esta praça

\footnotetext{
Este artigo foi desenvolvido no âmbito do projecto de investigação Creatcity - uma cultura de governança para a cidade criativa: vitalidade

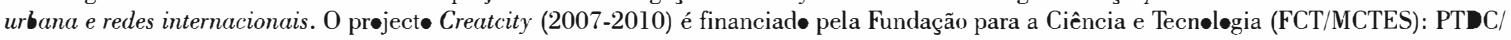
/AUR/65885/2006.

*Rutgers University, New Jersey.
} 
central constitui igualmente o lugar privilegiado de encontro dos cidadãos, onde os temas da cidade são debatidos e onde se formam as decisões políticas.

\section{Figura 1 - Ágora de Atenas:} o espaço público arquetípico

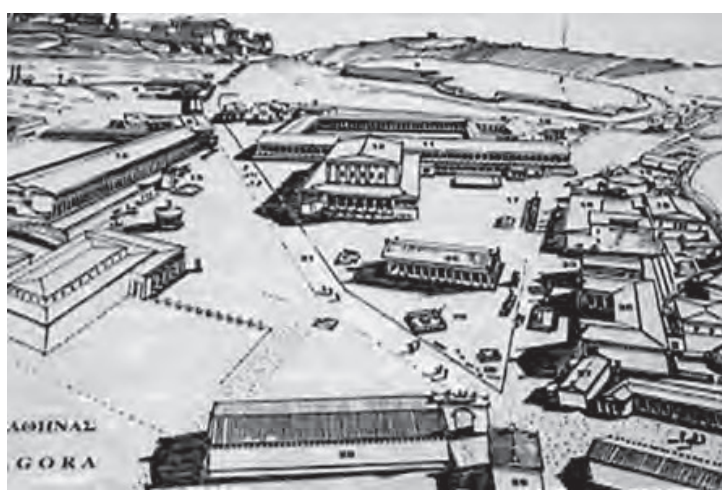

A este espaço público arquetípico - paisagem simbólica da democracia participativa - não são alheias, no entanto, as contradições. Aristóteles considerava a pólis uma "comunidade natural" cujo governo era directamente exercido pelos cidadãos, no entanto recomendava a interdição do espaço da ágora a uma parcela considerável dessa mesma comunidade (nomeadamente os trabalhadores, os agricultores, a maioria das mulheres e os escravos ${ }^{2}$ ). E tal como na pólis grega, muitos dos espaços públicos do passado - como o fórum romano, o mercado medieval, as avenidas e praças monumentais do Renascimento, ou os cafés boémios e os salões do Iluminismo - foram na verdade lugares relativamente pouco inclusivos, no sentido moderno do termo.

No entanto, a noção de que o espaço público deve ser um espaço equalitário, não excludente, e de livre acesso a todos os indivíduos é uma ideia central do actual debate teórico da cidade ${ }^{3}$. Vejamos algumas das definições de espaço público recentemente propostas. Espaços públicos são:

- Lugares urbanos abertos ao público que habitualmente congregam um elevado número de pessoas. (Barnett, 2003: 288)

- Territórios colectivos onde as pessoas prosseguem as actividades funcionais e rituais que unem uma sociedade, quer nas rotinas da vida quotidiana, quer em eventos cíclicos ou pontuais. (Carr et al., 1992: xi)

- Espaços que dão suporte, produzem, ou facilitam interacções sociais e culturais.

(Carmona et al., 2003: 114)

- Espaços que sugerem uma abertura e um livre acesso a todos (...) onde estranhos se encontram de forma equalitária e onde existe liberdade de expressão e de reunião entre cidadãos. (Warren, 2006)

- Lugares cuja manutenção é assegurada por entidades públicas em benefício da comunidade e que idealmente podem ser utilizados por todos os cidadãos, independentemente da sua condição social e económica, idade, raça, etnia, ou género. (Chapman, 2006)

Ainda que algumas das definições, retiradas do seu contexto, possam remeter para os actuais lugares virtuais da esfera pública (por exemplo: "espaços que dão suporte, produzem, ou facilitam interacções sociais e culturais"), todas elas se referem a territórios socioespaciais concretos, a lugares físicos da sociedade urbana que funcionam enquanto territórios colectivos e onde ocorrem encontros e trocas entre uma diversidade (idealmente universal) de cidadãos e actores da vida social.

É ainda possível identificar no conjunto destas definições três dimensões centrais ao conceito de espaço público: uma dimensão social - lugar primariamente vocacionado para a vida em sociedade; uma dimensão funcional - lugar onde ocorrem diversas actividades; e uma dimensão simbólica - lugar que concentra significados (mais ou menos) partilhados por diferentes pessoas/grupos sociais. Todos estes "lugares", por outro lado, indiciam territórios, sítios concretos onde estas dimensões coexistem. Para além daquilo que acontece no espaço público, é assim igualmente importante considerar aquilo que ele é, ou seja, os lugares físicos que o conformam, o palco no qual os actores sociais se movimentam. Para equacionar os temas da criatividade, vita-

\footnotetext{
${ }^{2}$ Stacy Warren, 2006.

${ }^{3}$ Encontramo-la por exemplo nas temáticas do espaço público enquanto lugar liminal de celebração da diferença e de encontro com o "outro"; enquanto lugar objectificado por pressões de privatização, comercialização e gentrificação; ou enquanto lugar de contestação e conflito.
} 
lidade e competitividade com as temáticas do espaço público interessa-nos abordar os espaços que facilitam a mobilidade cultural; onde se dão trocas imateriais de pontos de vista, de experiências de vida; onde é possível evoluir e mudar de perspectiva. Mas, numa época em que a esfera pública se tem vindo a desmaterializar em bits de comunicação instantânea, e em que entidades sociais e espaciais não coincidem necessariamente, interessa-nos sobretudo abordar os espaços relacionais onde o corpo está directamente investido no plano social; onde se pode viver a experiencia física da presença dos outros; e onde há um confronto dinâmico de diferentes significados/interpretações associados ao uso de um território comum.

Muitos dos teóricos da cidade preocupam-se, com boa razão, em estudar as novas geografias espaciais da cidade fragmentária e o novo meio (sub)urbano em que "a periferia substituiu o cen-

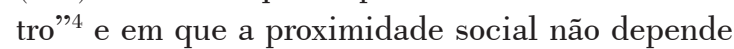
necessariamente da proximidade espacial. Com efeito, quando pessoas e actividades se distribuem no espaço em padrões cada vez mais dispersos, o espaço público perde parte das funções que outrora cumpriu na vida social da cidade: lugar de encontro para o debate político, para trocas comerciais, e para representações culturais. Da mesma forma, quando as redes de comunicação instantânea criam novas arenas de debate e sistemas de troca que não dependem do espaço físico nem de contactos face-a-face, a importância dos espaços urbanos vê-se gradualmente diminuida (Balula, 2008). Nesse sentido procura-se hoje perceber e codificar as formas suburbanas emergentes ${ }^{5}$ e também as formações sociais emergentes nos "espaços públicos" inovadores da sociedade em rede, na qual a importância dos lugares tradicionais (físicos/materiais) de encontro parece ter diminuído francamente, face às potencialidades virtuais dos lugares de encontro electrónico.

Esta desterritorialização da esfera pública, no entanto, sugere deslocamentos de sentido que exigem uma abordagem crítica. $\mathrm{O}$ mapear destas novas geografias não implica necessariamente a aceitação tácita de uma "cidade de fluxos" enquanto condição estrutural inescapável, cujas consequências - nomeadamente a erosão da "cidade de lugares"
- devamos abraçar sem questionar. Como diversos autores têm vindo a afirmar (pe., Hall, 1998; Acs, 2002; Hospers, 2003; Walters and Brown, 2005), ainda que a rede digital global constitua uma infra-estrutura com o potencial para alterar de forma dramática a morfologia da cidade tradicional, o poder do lugar prevalecerá, pois as pessoas continuam a valorizar os contactos face-a-face, e tendem a gravitar para os lugares físicos onde as transacções humanas possuem qualidades únicas, impossíveis de transmitir através de um cabo. Contrariamente às expectativas da "morte do lugar" veiculadas primeiramente por Melvin Webber (1964) a propósito do advento da massificação do uso do automóvel e posteriormente ampliadas pela ideia da "morte da geografia" veiculada pelos tecnofuturistas durante a fase inicial da revolução tecnológica do final do século xx (pe. Mitchell, 1995; Kelly, 1998; Gilder, 2000), a realidade (e a investigação actual) tem vindo a demonstrar o oposto: a importância e o valor do lugar tende a aumentar apesar (ou precisamente por causa) da dimensão não-espacial do "espaço" electrónico e das redes sociais digitais. Conforme Richard Florida notou, os lugares urbanos mais atraentes para as classes criativas são aqueles que oferecem uma diversidade de experiências, uma variedade de actividades, e possibilitam diferentes estilos de vida (Florida 2002:11). Tal como Florida, também Joel Garreau acredita que o principal objectivo da cidade do futuro deverá ser a provisão de condições óptimas para os contactos face-a-face, uma antiga mas primária necessidade humana (Garreau, 2001). Neste contexto, o espaço público da cidade tradicional surge enquanto o meio urbano por excelência, onde estas actividades humanas têm mais hipóteses de florescer.

Por outro lado, criatividade, vitalidade e competitividade urbanas são frequentemente atribuídas aos territórios paradigmáticos do dinamismo empresarial, investimento financeiro e sucesso económico, como Sillicon Valley ou os parques empresariais onde se estimula a inovação e o progresso tecnológico. No entanto, ainda que servidos por uma rede de comunicações e informação que liga intensivamente todos os nós do sistema, os padrões de vida social de um parque tecnológico são, regra geral, extremamente limitados. Um parque tecnológico

\footnotetext{
${ }^{4}$ Michael Dear, 2000:14. Dear chega a afirmar que “o telefone e o modem tornaram já a rua irrelevante". (Dear, 1995:31).

${ }^{5}$ Cf., por exemplo, Domingues, 2010.
} 
"não faz cidade" e, como afirma o cientista político Langdon Winner a propósito da vida social em Silicon Valley, "quem habita a região . . . encara hoje uma mancha caótica de estradas, longas horas no trânsito e padrões de vida social cheios de stress." (Winner, 2006: 1095)

Figura 2 - Parque tecnológico em Sillicon Valley

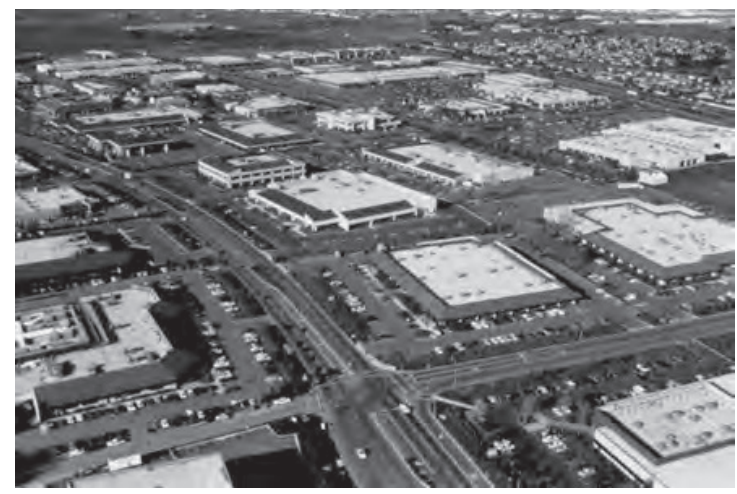

Interessa-nos assim estudar os espaços públicos de sucesso da cidade histórica tradicional - as ruas, praças e jardins de bairros que possuem ainda uma vida social vibrante - pois estas áreas urbanas centrais não só constituem um repositório de boas práticas de fazer cidade, como comprovaram já possuir robustez e flexibilidade suficientes para se adaptar, repetidas vezes, aos mais diversos processos de transformação urbana e social. Perante as incertezas formais e a crescente insustentabilidade da cidade sem modelo, é nestes espaços - e através das suas redes sociais complexas - que a criatividade e vitalidade urbanas, sobretudo no que toca às actividades culturais, encontram um território de excepção para se desenvolver. Com efeito, e conforme tem vindo a ser crescentemente apercebido por diversos autores, é muito provável que os espaços públicos tradicionais de determinadas áreas urbanas venham a tornar-se precisamente nos locais indispensáveis às actividades e interacções colectivas de uma sociedade electronicamente conectada, mas socialmente atomizada.

\section{Tipologias de espaços urbanos}

Em 1748 o arquitecto italiano Giambattista Nolli completa o primeiro levantamento cartográfico detalhado da cidade de Roma. O mapa resultante - hoje conhecido como o Mapa de Nolli - constitui um documento exemplar para o entendimento e estudo do espaço público urbano.

\section{Figura 3 - Detalhe do Mapa de Nolli} (Roma, 1748)

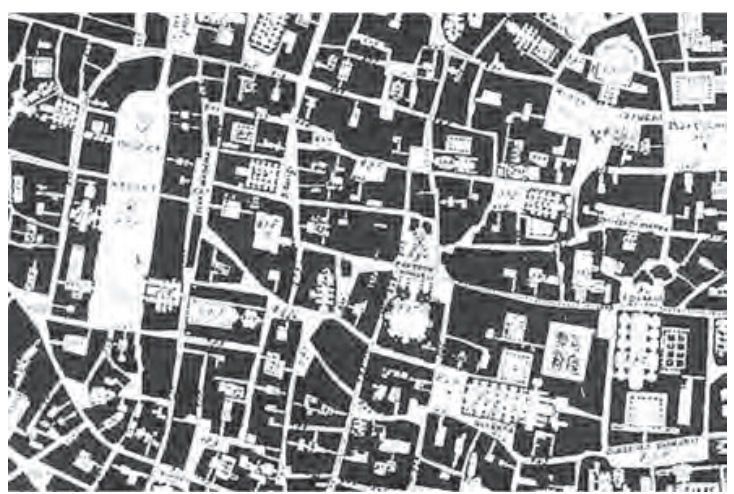

Nolli utiliza uma técnica já conhecida na época - a técnica de figura-fundo, em que os elementos sólidos (edifícios e quarteirões) são representados a negro e os espaços vazios (ruas e praças) a branco. No entanto, introduz uma importante inovação: neste mapa ele representa igualmente a branco o interior dos edifícios públicos ${ }^{6}$, o que nos dá, pela primeira vez, uma percepção visual inteiramente diferente da composição do espaço urbano. É que, ao incluir certos espaços interiores enquanto prolongamento dos espaços públicos exteriores Nolli está, de facto, a cartografar os lugares da esfera pública na Roma do seu tempo.

Este tipo de representação permite-nos distinguir três tipos de espaços urbanos, nomeadamente: espaços privados, espaços públicos, e espaços privados acessíveis ao público. E, se fosse possível assistir, como num filme rápido, à evolução temporal do mapa de Nolli observar-se-ia um facto interessante: enquanto que as duas primeiras categorias permaneceriam praticamente imutáveis, assistiríamos a uma intensa dinâmica de transformação nos espaços privados de acesso público: muitos deles simplesmente desapareceriam, enquanto que novas áreas em branco surgiriam escavadas nos blocos negros dos quarteirões.

A dinâmica de transformação dos espaços privados acessíveis ao público tem directamente a ver com a dinâmica de transformação das actividades

\footnotetext{
${ }^{6}$ À data, predominantemente igrejas e capelas, mas também diversos colégios, alguns palácios, e as múltiplas arcadas existentes.
} 
(usos do solo) que funcionam enquanto magnetos de pessoas. Enquanto que hoje certas actividades económicas - como cinemas e auditórios, bares e restaurantes, mercados e comércio diverso - exercem uma natural atracção e vivem essencialmente do contacto com as pessoas que passam nas ruas, outras actividades - como armazéns, blocos exclusivamente habitacionais ou de escritórios, indústria pesada, ou grandes superfícies comerciais - suscitam poucas relações com o exterior. Do ponto de vista da vitalidade do espaço urbano, as actividades mais relevantes - e com maior interesse para o nosso estudo - são precisamente aquelas que ocorrem nos espaços privados de uso público e que produzem um grande número de transacções humanas entre o interior e o exterior dos edifícios.

É necessário reconhecer que a vasta maioria dos actuais espaços privados de uso público não são de acesso livre, pois alojam actividades económicas que exigem geralmente o pagamento de um ingresso, ou o consumo de algum tipo de produto ou serviço. Com efeito, há um grande défice de espaços interiores públicos, ou "salas de estar" urbanas, na cidade actual, onde seja possível permanecer sem pagar ou consumir algo. No entanto, apesar desta forte limitação em termos de acessibilidade universal, os espaços privados acessíveis ao público constituem uma importante extensão do espaço público da rua e influem decisivamente na vitalidade do espaço urbano. A permeabilidade dos edifícios, ou melhor, a forma como as actividades 'de dentro' dos edifícios transbordam para fora deles, dado o seu grau de atractividade, é assim um factor importante para o estudo da dinâmica do espaço público urbano.

Jan Gehl no seu já célebre clássico Life Between Buildings (1971), identificou a existência de três categorias distintas de actividades humanas nos espaços públicos: actividades necessárias, sociais e opcionais. Partindo desta nomenclatura, e associando-a às actividades económicas que ocorrem nos espaços privados acessíveis ao público, podemos igualmente distinguir as actividades necessárias predominantemente dirigidas para a comunidade local e que satisfazem necessidades estritamente funcionais (por ex.: o comércio diário de proximidade, bancos e consultórios, ou estabelecimentos de ensino e de saúde); as actividades sociais - que dependem da presença simultânea de muitas pessoas e satisfazem as necessidades gregárias e de convívio informal da comunidade (por ex.: cinemas e teatros, bares e restaurantes, ou associações culturais); e as actividades opcionais - que satisfazem necessidades específicas de determinados sectores da sociedade (por ex.: hotéis, museus e galerias de arte, antiquários, ou bibliotecas e livrarias). Diferentemente das actividades necessárias, quer as actividades sociais quer as actividades opcionais possuem um grau de atractividade supralocal.

A presença de actividades opcionais, conforme observou Gehl, resulta num aumento significativo dos contactos e interacções humanas, reforçando o papel aglutinador das actividades sociais. Por outro lado, o argumento central de Gehl, preconizando que os espaços públicos de menor qualidade são precisamente aqueles onde ocorrem apenas actividades necessárias, sugere que a vitalidade do espaço público de uma área urbana e, consequentemente, o seu potencial de criatividade e competitividade relativamente a outras áreas, depende da presença de um elevado número de actividades opcionais e sociais.

\section{Multifuncionalidade e densidade}

A este respeito importa referir ainda duas outras qualidades, habitualmente reconhecidas enquanto fundamentais à vitalidade do espaço público urbano ${ }^{7}$ : a multifuncionalidade e a densidade.

As áreas urbanas podem ser multifuncionais isto é, conter em si uma diversidade de funções, ou actividades - porque contêm edifícios de usos mistos (por ex.: comércio no rés-do-chão e habitação nos pisos superiores), ou porque contêm uma mistura de edifícios monofuncionais destinados a usos diferenciados. A teoria sugere que do ponto de vista da vitalidade do espaço urbano o primeiro tipo é geralmente preferível (Carmona et al., 2003, 179-82).

Áreas urbanas onde ocorre uma multiplicidade de funções diversas, onde está sempre a acontecer qualquer coisa, dia e noite, e onde, consequentemente, a possibilidade de encontros casuais é maior - diz Jacobs (1969) - são os lugares com o maior potencial de empreendedorismo, inovação e criati-

\footnotetext{
${ }^{7}$ Cf. por ex.: Jacobs, J., 1961, 1969; Lynch, 1981; Lozano, 1990; Jacobs, A., 1993.
} 
vidade $^{8}$. Conforme referido por Hospers (2003:150), alguns estudos recentes (Quigley, 1998; Glaeser, 2000; Van Oort, 2003) que testaram empiricamente as ideias de Jacobs vieram comprovar que as áreas urbanas multifuncionais, quer nos EU, quer na UE, têm dinâmicas de crescimento mais acentuadas que as áreas urbanas monofuncionais, em termos económicos, sociais e espaciais.

A densidade de residentes e utentes de uma área urbana, por outro lado, é um factor importante para garantir uma massa crítica que viabilize um elevado número de actividades diversas. A concentração de um elevado número de pessoas numa dada área, no entanto, é uma condição necessária, mas não suficiente, para estimular a sua criatividade. A criatividade urbana depende sobretudo da densidade de interacções entre os actores sociais. $O$ potencial de criatividade de uma dada área urbana será assim tanto maior quanto maior for o número de actividades nela presentes que favoreçam encontros e contactos interpessoais frequentes, que por sua vez estimulam o debate de ideias, a crítica e a inovação.

O papel da aglomeracão é fundamental para a criatividade (Costa et al., 2007) e algumas áreas centrais da cidade tradicional - que associam um forte valor simbólico a uma elevada densidade e multiplicidade de actividades, particularmente as opcionais e sociais - possuem espaços públicos de grande vitalidade e são naturalmente propícias à emergência de actividades criativas.

\section{Figura 4 - Espaço público de uma área urbana central}

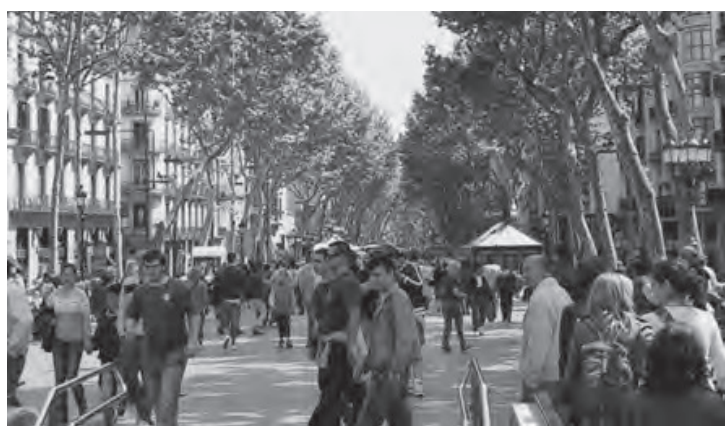

A concentração espacial de actividades diversas numa malha urbana densa como a destes bairros centrais determina ainda uma outra característica fundamental à vitalidade do espaço público: a facilidade de nele se poder andar a pé (walkability). Contrariamente ao espaço urbano da cidade extensa, onde as actividades se situam distantes umas das outras em lugares apenas acessíveis de carro, os espaços públicos das áreas urbanas centrais onde haja uma intensa concentração de actividades interligadas por ruas e praças acessíveis e confortáveis para os peões multiplica os contactos humanos informais, favorece o desenvolvimento de redes sociais de proximidade, e constitui um território privilegiado para a inserção de actividades criativas.

\section{Estudos de caso}

Neste estudo analizam-se três bairros distintos que aparentemente reúnem as condições acima descritas. São áreas urbanas multifuncionais, cujos espaços públicos possuem uma vitalidade notável, organizadas numa malha densa de ruas, onde ocorre uma grande diversidade de actividades sociais e opcionais em espaços privados de uso público.

Do ponto de vista urbanístico, os bairros em análise - Bairro Alto, em Lisboa; Vila Gracia, em Barcelona; e Vila Madalena, em São Paulo foram seleccionados por possuirem um conjunto de características únicas que os distinguem, e cujo carácter "histórico" não tem impedido a sua transformação, nomeadamente através da assimilação de novos usos que lhes têm vindo a imprimir dinâmicas sociais inovadoras e criativas. Com efeito, estes bairros, informalmente identificados e reconhecidos enquanto "bairros culturais", reúnem muitas das características das "vilas urbanas" de Tony Aldous ${ }^{9}$ e dos bairros ideais conceptualizados pelos proponentes de um "novo urbanismo"10, nomeadamente:

- Uma dimensão suficientemente pequena para que a distância entre os diversos lugares seja

\footnotetext{
${ }^{8}$ Jane Jacobs identificou quatro pré-condições para a criação e preservação de bairros vibrantes e com diversidade: (1) grande densidade de população e de actividades; (2) mistura de usos; (3) ruas e quarteirões de pequena dimensão e amigáveis para o peão; (4) manutenção de edifícios antigos misturados com outros mais modernos.

${ }^{9}$ Cf. Aldous, 1992

${ }^{10} \mathrm{Cf}$. CNU, 1998; Balula, 2000.
} 
facilmente percorrível a pé ${ }^{11}$ e para que as pessoas tenham a possibilidade de conhecer-se; mas suficientemente grande para permitir um leque alargado de actividades diversas, bem como um serviço de transportes públicos.

- Uma concentração de actividades cívicas, culturais, institucionais e comerciais, que proporciona uma diversidade de pontos de encontro, quer formais quer informais.

- Uma diversidade de usos, não só no bairro em geral mas também em cada quarteirão.

- Uma malha densa de ruas interligadas, conformando quarteirões de dimensões relativamente pequenas, que possibilitam múltiplas escolhas de percursos alternativos e encorajam o andar a pé.

- Um ambiente confortável e seguro para os peões, que admite o automóvel sem no entanto privilegiar o seu uso.

- Uma combinação de edifícios de diferentes tipos e dimensões, incluindo um elevado número de edifícios de usos mistos ${ }^{12}$.

- Uma concentração de edifícios "robustos", isto é, com o potencial para se adaptar a diferentes usos, conforme as necessidades de diferentes épocas.

- Uma relação aproximadamente equilibrada entre quantidade de empregos e quantidade de unidades residenciais ${ }^{13}$.

- Um elevado nível de actividade a diferentes horas do dia, bem como uma economia nocturna que proporciona lugares de lazer, encontro e entretenimento.

Interessou-nos, neste estudo exploratório, perceber as dinâmicas dos espaços públicos dos bairros em questão em termos da sua funcionalidade, acessibilidade e morfologia; bem como a percepção dos actores locais das relações entre estes factores urbanísticos e a criatividade, vitalidade e competitividade de cada bairro.
Metodologicamente, a primeira parte do inquérito realizou-se através de um levantamento funcional em que se registaram todas as actividades actualmente existentes, e que incluem um total de vinte e oito tipologias distintas. Paralelamente fez-se ainda um levantamento sumário do nível de serviço dos transportes públicos; e realizou-se um levantamento fotográfico exaustivo dos três bairros, em que se procurou captar as dinâmicas dos espaços públicos a diferentes horas do dia e também de noite.

A segunda parte do inquérito contou com uma série de vinte e duas entrevistas, realizadas a actores-chave locais, em que se investigou a sua percepção do bairro respectivo em termos de criatividade, vitalidade e competitividade, e de onde se extraíram as principais referências a aspectos urbanísticos, funcionais e espaciais ${ }^{14}$.

\section{Análise urbanística e espacial}

Ainda que de dimensões variáveis - Bairro Alto com uma área de cerca de 21 ha; Vila Gracia com cerca de 96 ha; e Vila Madalena com cerca de 89 ha - os três bairros possuem uma morfologia semelhante, sendo formados integralmente por malhas ortogonais irregulares. A diversa génese dos bairros determina, no entanto, importantes diferenças ${ }^{15}$. O Bairro Alto, mais antigo, apresenta traçados mais orgânicos, ruas e quarteirões mais estreitos, e nenhuma praça (as existentes situam-se todas nas periferias do bairro); Vila Gracia, por outro lado, distingue-se precisamente por um elevado número de praças, no seio de uma malha compacta de ruas conformando quarteirões de dimensão variável; e Vila Madalena, com um traçado mais rígido e regular (mais puramente ortogonal) distingue-se pela maior largura das ruas e pela dimensão dos quarteirões, substancialmente maior que em qualquer dos outros casos.

\footnotetext{
${ }^{11}$ Correspondente a uma distância máxima de 600 metros, ou o equivalente a cerca de 7 minutos a pé entre os lugares mais centrais do bairro e os lugares mais distantes

${ }^{12}$ Por exemplo residencial e comercial, ou residencial e escritórios.

${ }^{13}$ Idealmente numa relação de 1:1.

${ }^{14} \mathrm{O}$ trabalho de campo decorreu nas três cidades em períodos distintos, entre 2008 e 2009.

${ }^{15}$ Ver descrições pormenorizadas da génese e evolução dos três bairros em: Roldão, Vasconcelos e Latoeira, "Um Estudo sobre as Cidades Criativas-Apresentação do diagnóstico aos estudos de caso: Lisboa, São Paulo e Barcelona" (2010), artigo produzido no âmbito do projecto Creatcity, no qual o presente estudo igualmente se insere.
} 
Figura 5 - Mapas figura-fundo dos bairros

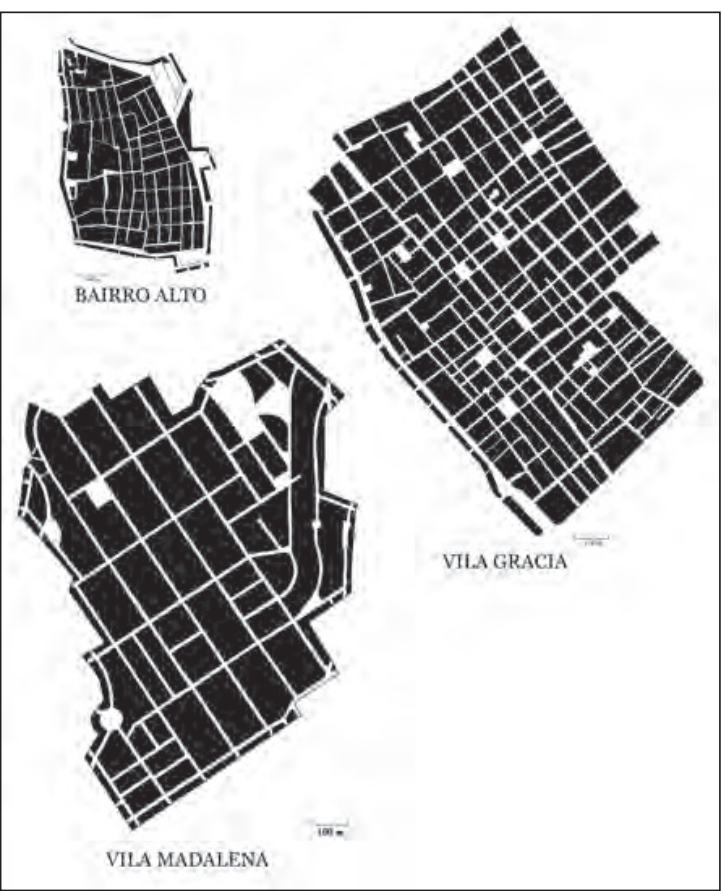

Morfologicamente existem ainda outras importantes distinções a assinalar. Assim, quer as ruas do Bairro Alto - com edifícios predominantemente de 3 e 4 pisos - quer as ruas de Vila Gracia - com edifícios predominantemente de 4 e 5 pisos - são ruas-canal bastante estreitas, ambas com uma relação típica de 1:2 entre a largura da rua e a altura das fachadas dos edifícios, o que determina que o espaço público seja bastante fechado e contido. Já em Vila Madalena esta relação é tipicamente de $3: 1$, o que significa um espaço público muito mais aberto e menos contido, ainda que em determinados lugares a existência de árvores nos passeios contribua para uma sensação de maior fechamento espacial. Em Vila Gracia as inúmeras praças, ainda que de pequena dimensão, constituem lugares de abertura visual no interior da malha fechada de ruas. No Bairro Alto, por outro lado, a malha fechada é interrupta, as praças são todas exteriores ao bairro e funcionam enquanto "átrios" e "portas de entrada" do bairro.

Figura 6 - Secções-tipo dos bairros

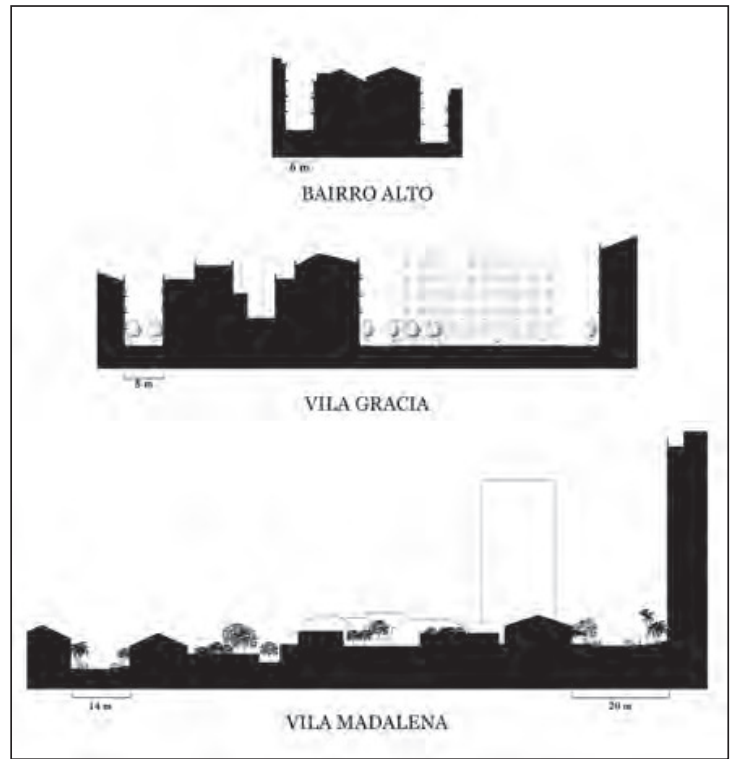

Interessou-nos ainda analisar comparativamente a distribuição de espaço livre público (ruas e praças) e de espaço privado (as implantações dos quarteirões), por forma a avaliar, para cada caso, a área de espaço público em relação à área total do bairro. Assim, conforme se pode observar o quadro da Figura 7, enquanto que no Bairro Alto os espaços públicos abrangem praticamente $1 / 4$ da totalidade da área do bairro, em Vila Gracia, que possui ruas um pouco mais largas e um grande número de praças, os espaços públicos representam já $1 / 3$ da área total do bairro. Vila Madalena, devido às suas ruas francamente mais largas e à existência de duas grandes praças, apresenta a maior percentagem de espaço público $(41 \%)$ relativamente à totalidade da área do bairro.

Figura 7 - Relação espaço público/espaço privado

BAIRRO ALTO

VILA GRACIA

VILA MADALENA

\begin{tabular}{lccc}
\hline Área Total do Bairro & 21,4 ha & 96,4 ha & 89,0 ha \\
\hline Área Espaço Privado & 14,3 ha & 64,9 ha & 52,8 ha \\
\hline Área Espaço Público & 5,2 ha $=24 \%$ & 31,4 ha $=33 \%$ & 36,2 ha $=41 \%$
\end{tabular}


Quanto à segurança e conforto pedonal dos espaços públicos, quer Vila Gracia quer o Bairro Alto são ambientes urbanos amigáveis para o peão onde é fácil, e pode ser agradável, andar a pé. A dimensão dos quarteirões em ambos os casos é pequena, o que multiplica as alternativas de percurso origem-destino; existem diversas ruas pedonalizadas, ou de trânsito automóvel limitado; e há um grande número de fachadas activas que atraem o olhar e animam os percursos pedonais. A relação peão/ /automóvel é mais ordenada em Vila Gracia - onde há passeios confortáveis e bem delimitados para a circulação de peões, de nível com a faixa de rodagem - que no Bairro Alto, onde os passeios estreitos e desnivelados da via de circulação automóvel, bem como separadores mal colocados, dificultam e tornam mais inseguras as deslocações pedonais.

Vila Madalena, por outro lado, é claramente um bairro motorizado. Ainda que os passeios, mais amplos, constituam um espaço de estar e circular seguro e activamente apropriado pelas pessoas, os quarteirões são demasiado longos para grandes percursos a pé, e os possíveis destinos distribuem-se de um modo mais disperso. A própria paisagem urbana, em contraste com os outros dois bairros, é em grande parte dominada pela presença constante do automóvel.

Figura 8 - Espaços públicos característicos do Bairro Alto

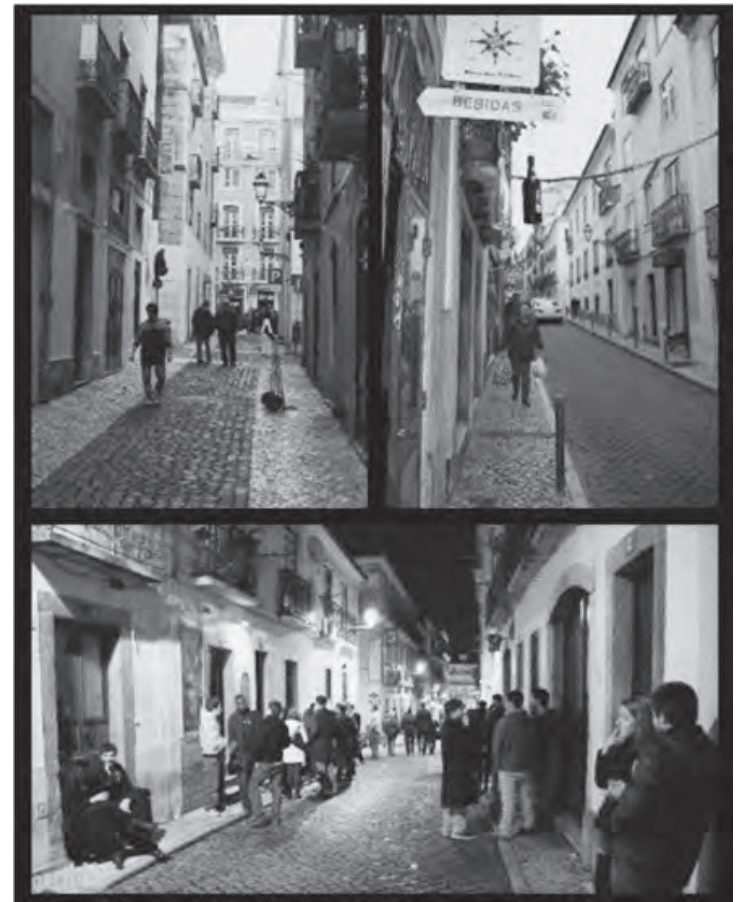

Figura 9 - Espaços públicos característicos de Vila Gracia

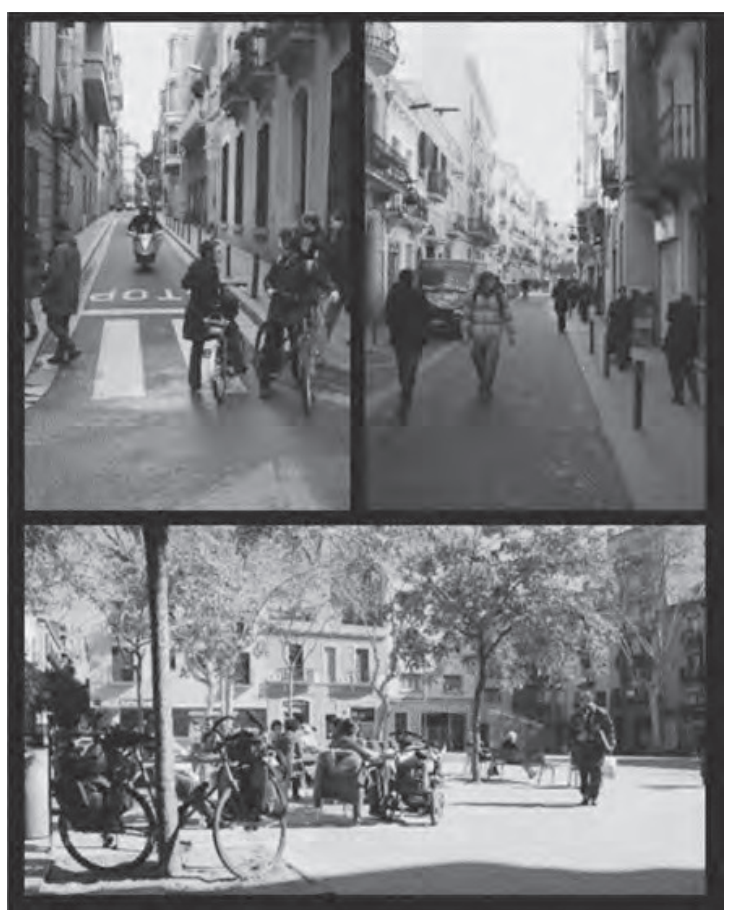

Figura 10 - Espaços públicos característicos de Vila Madalena

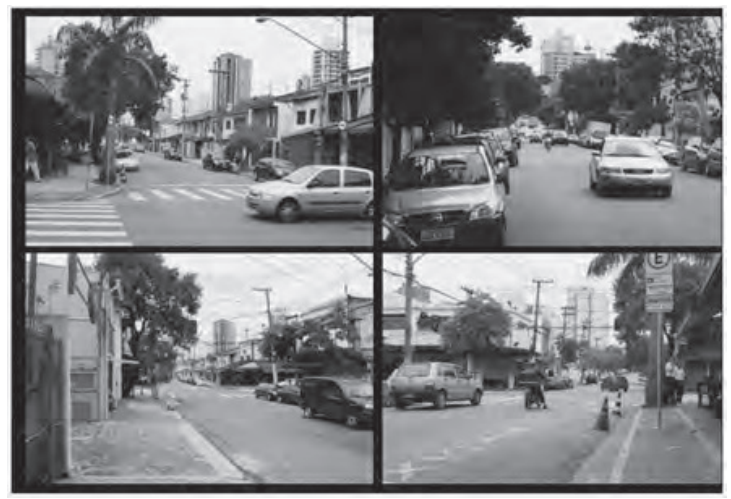

De entre os três bairros Vila Madalena é, comprovadamente, o menos pedonal (walkable) e onde as pessoas dependem mais do automóvel para a sua vida quotidiana. Isto mesmo é demonstrado pelo modelo "Walk Score"16, que avalia o grau de

16 "Walk Score" é um algoritmo que calcula a pedonalidade (walkability) de um endereço baseado na distância a que ele se encontra de uma série de actividades urbanas. O que é medido é a possibilidade de se ter um estilo de vida não dependente do automóvel para o dia-a-dia. $\mathrm{O}$ algoritmo inclui as seguintes actividades: mercearias e supermercados, restaurantes, cafés, bares, cinemas, escolas, parques, bibliotecas, livrarias, ginásios, farmácias, lojas de ferragens, lojas de vestuário e lojas de audiovisuais. O rigor do método depende do rigor dos registos actualizados do "Google Maps", no qual se baseia. $\mathrm{O}$ website http://www.walkscore.com/, onde é possível realizar estes cálculos, foi lançado em 2007 e tem vindo desde aí a ser desenvolvido e aperfeiçoado. 
pedonalidade (walkability) de uma determinada área urbana.

Procedeu-se a um cálculo comparativo dos três bairros de acordo com o modelo "Walk Score". Dado que o método permite apenas medir a pedonalidade de localizações pontuais, seleccionaram-se em cada bairro cinco localizações (uma central e as outras quatro em áreas a norte, sul, este e oeste) por forma a obter um valor agregado para o bairro. De acordo com os cálculos, descritos no quadro da Figura 11, o Bairro Alto destaca-se enquanto o mais pedonal (a walker's paradise), onde a maioria das necessidades quotidianas podem ser supridas a pé, e é perfeitamente possível viver sem carro. Vila Gracia apresenta maiores variações de acessibilidade interna, mas em geral é um bairro bastante pedonal, onde no entanto o acesso a algumas das actividades essenciais requer uma bicicleta, moto, transporte público, ou carro. Vila Madalena, por outro lado, surge enquanto um bairro onde as pessoas definitivamente dependem de algum tipo de transporte para aceder a uma grande parte das suas necessidades.

\section{Figura 11 - "Walk Score"} - uma medida de pedonalidade ${ }^{17}$

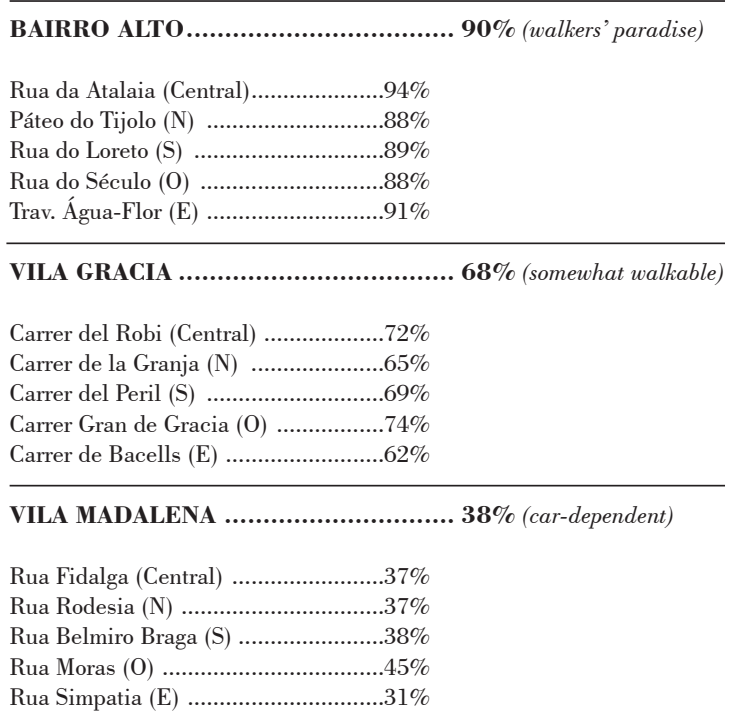

Um factor essencial de vitalidade e também de sustentabilidade urbana, a pedonalidade dos bairros, é portanto em grande parte determinada quer pelo tipo de actividades neles existentes (em espaços privados de uso público), quer pelo seu grau de concentração ou dispersão.

Por forma a avaliar a dinâmica actual dos espaços privados de uso público - que funcionam enquanto magnetos de pessoas e contribuem para a vitalidade do bairro - procurou-se identificar e localizar as actividades existentes em cada bairro, por forma a perceber a sua composição e distribuição espacial. Nos levantamentos funcionais realizados cartografaram-se as localizações de todas as actividades urbanas existentes. De acordo com a metodologia proposta, as vinte e oito tipologias de actividade identificadas foram agrupadas em três tipos: 1) actividades necessárias - predominantemente dirigidas para a comunidade local e que satisfazem as necessidades estritamente funcionais da comunidade; 2 ) actividades sociais - que dependem da presença simultânea de muitas pessoas e satisfazem as necessidades gregárias e de convívio informal da comunidade; e 3) actividades opcionais - que satisfazem necessidades específicas de determinados grupos sociais (ver quadro da Figura 12).

\section{Figura 12 - Actividades urbanas:} Necessárias, Sociais e Opcionais

\section{Actividades urbanas:}

\section{Necessárias}

satisfazem as necessidades funcionais da comunidade

- Comércio tradicional "de proximidade"

- Oficinas tradicionais

- Estabelecimentos de Ensino

- Estabelecimentos de Saúde

- Estabelecimentos de Apoio Social

- Estabelecimentos Administrativos

- Estabelecimentos de Segurança Pública

- Bancos

- Escritórios e Consultórios

\footnotetext{
${ }^{17} \mathrm{http}: / /$ www.walkscore.com / (accessed 28.01.2010):

$90-100 \%=$ Walkers' Paradise: Most errands can be accomplished on foot and many people get by without owning a car $70-89 \%$ = Very Walkable: It's possible to get by without owning a car.

$50-69 \%$ = Somewhat Walkable: Some stores and amenities are within walking distance, but many everyday trips still require a bike, public transportation, or car.

$25-49 \%$ = Car-Dependent: Only a few destinations are within easy walking range. For most errands, driving or public transportation is a must. 0-24\% = Car-Dependent (Driving Only): Virtually no neighborhood destinations within walking range. You can walk from your house to your car!
} 


\section{Sociais}

satisfazem as necessidades gregárias e de convívio da comunidade

- Bares, Cafés, Cervejarias e Restaurantes

- Cinemas Teatros e Auditórios

- Associações Promotoras de Actividades Culturais

- Associações Cívicas

\section{Opcionais}

satisfazem as necessidades de sectores específicos da sociedade

- Comércio de "imagem criativa"

- Comércio de grandes cadeias

- Oficinas "criativas"

- Bibliotecas e Arquivos

- Galerias de Arte

- Ateliers de Artistas

- Antiquários

- Livrarias e Alfarrabistas

- Estabelecimentos de Ensino Artístico

- Museus e Grandes Equipamentos Culturais

- Estabelecimentos hoteleiros

Conforme esperado, o número total de actividades em espaços privados de uso público é bastante elevado no Bairro Alto e em Vila Gracia, enquanto que é comparativamente bastante mais moderado em Vila Madalena.

Vila Gracia regista a maior concentração de actividades necessárias (comércio diário, oficinas, serviços públicos, etc.) e também de actividades opcionais (comércio "criativo", livrarias, grandes cadeias, galerias de arte, etc.). O Bairro Alto regista a maior concentração de actividades sociais (restaurantes, bares, associações culturais, etc.) e também um elevado número de actividades opcionais. No caso de Vila Madalena - onde se confirma uma comparativamente baixa concentração de actividades de qualquer género - a incidência dos três tipos é, no entanto, relativamente equilibrada (ver quadro da Figura 13).

Figura 13 - Concentração de actividades urbanas

(n. ${ }^{\circ}$ de unidades em 10 hectares $^{18}$ )

\begin{tabular}{lcccc} 
& Necessárias & Sociais & Opcionais & Total \\
\hline BAIRRO ALTO & 50 & 110 & 100 & 260 \\
\hline VILA GRACIA & 80 & 40 & 110 & 230 \\
\hline VILA MADALENA & 20 & 30 & 20 & 70 \\
\hline
\end{tabular}

Os mapas das Figuras seguintes ilustram a concentração do tipo de actividades dominantes em cada um dos bairros estudados.

Figura 14 - Bairro Alto: actividades sociais

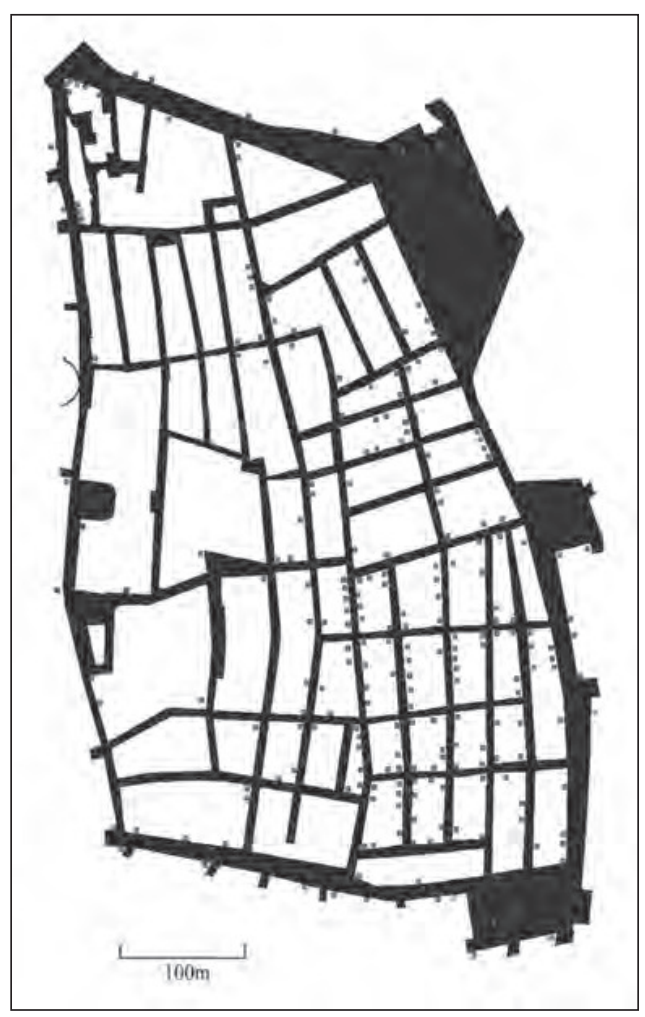

Figura 15 - Vila Gracia: actividades opcionais

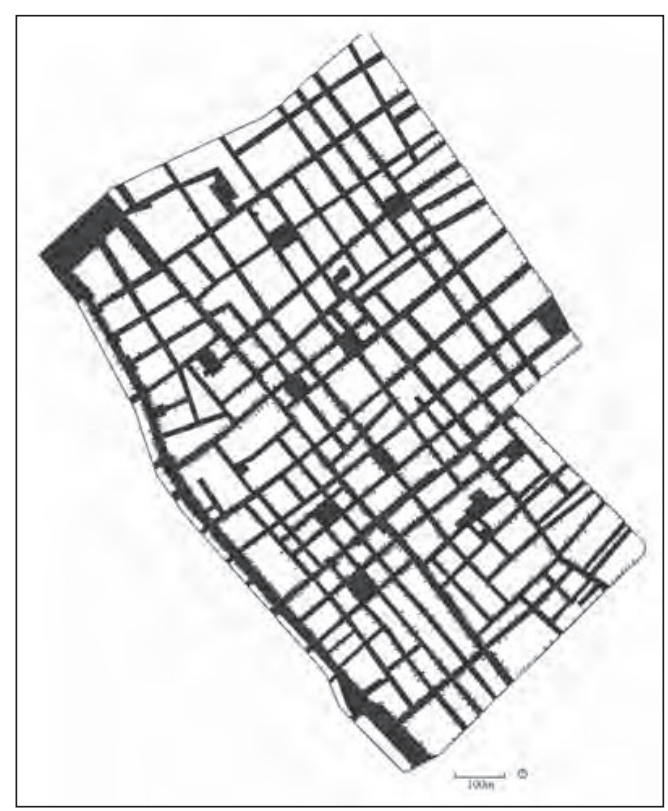

${ }^{18}$ Arredondado às dezenas. 
Figura 16 - Vila Madalena: actividades sociais

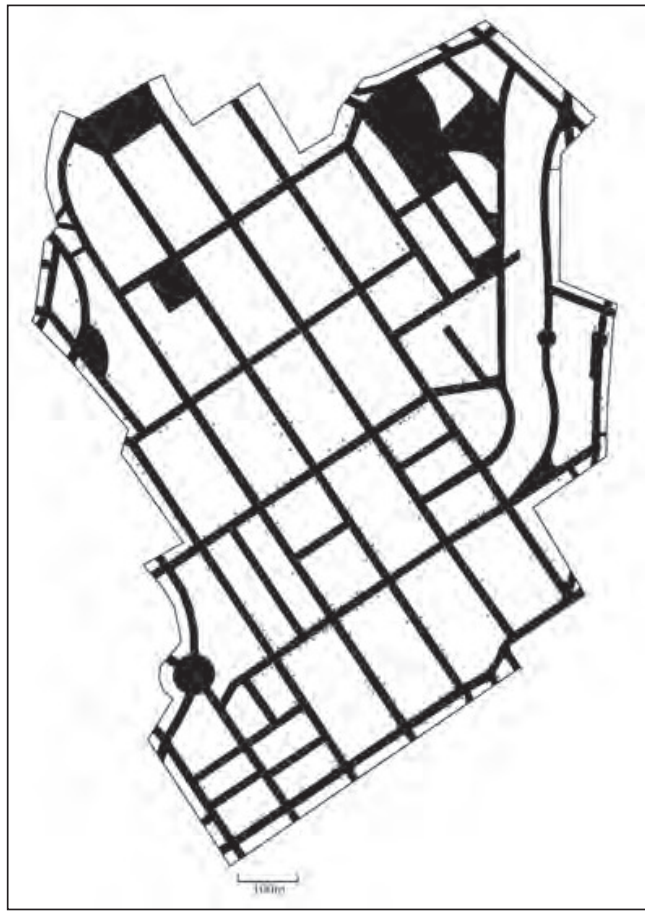

Percepção dos agentes locais

Realizou-se ainda uma série de entrevistas exploratórias a diversos actores-chave em cada cidade ${ }^{19}$ por forma a obter, a partir do conhecimento local, uma visão partilhada e uma apreciação qualitativa do bairro respectivo. Destas entrevistas emerge um grupo de qualidades comuns aos três bairros, apontadas pelos inquiridos enquanto factores específicos que os distinguem de outras áreas urbanas da mesma cidade. São eles:

- Um espaço público fortemente marcado pela presença de comércio.

- Um espaço público onde há boas condições de acessibilidade e mobilidade.

- Um espaço público facilmente apropriável.

- Um ambiente propício à emergência de comércio inovador.

- Existência de equipamentos culturais.

- Existência de vida nocturna.

- Um bairro associado à ideia de "vida boémia."
- Existência de um conflito (ruído) entre a vida nocturna e alguns residentes.

- Uma mistura de elementos (edifícios, comércios, espaços) contemporâneos com elementos tradicionais.

Enquanto factores específicos que contribuem para a criatividade dos bairros, os entrevistados apontaram em comum os seguintes tópicos:

- Existência de instituições criativas; o bairro constitui um ponto de encontro de indivíduos e grupos criativos.

- Existência de comércio e serviços inovadores, como ateliers artísticos, oficinas de artesanato criativo, galerias de arte, etc.

- Existência de lojas e bares "personalizados".

- Uma renovação e um rejuvenescimento da população residente.

Enquanto factores específicos que contribuem para a competitividade dos bairros, os entrevistados apontaram em comum:

- A orientação para o mercado exterior.

- A existência de animação nocturna.

- A existência de comércio inovador (design, galerias de arte, etc.).

De acordo com os entrevistados, em Vila Gracia destacam-se ainda duas outras qualidades que distinguem o bairro dos demais: uma forte tradição e identidade própria; e a presença de um tecido associativo muito activo, que contribui para um forte sentido comunitário. Esta forte tradição associativa e cultural é precisamente apontada enquanto factor diferenciador face a outros bairros de Barcelona e decisivo para a competitividade do bairro.

Em Vila Madalena são ainda apontados enquanto factores diferenciadores específicos, uma elevada presença de estudantes e universitários residentes (proximidade da Universidade de São Paulo) e, pela negativa, um excesso de tráfego automóvel.

No Bairro Alto, para além dos factores comuns

\footnotetext{
${ }^{19} 22$ no total: 8 no Bairro Alto; 8 em Vila Gracia; 6 em Vila Madalena. Os entrevistados incluem: consultores de desenvolvimento urbano, de políticas públicas e de indústrias criativas; agentes de instituições ligadas à produção e organização de actividades culturais; agentes da administração pública local (municípios, ayuntamentos ou prefeituras); actores institucionais e governamentais (níveis central, regional ou federal); e agentes decisivos no pensamento da cidade (urbanismo, desenvolvimento económico e/ou social). Para uma descrição pormenorizada das entrevistas e dos agentes entrevistados ver Roldão, Vasconcelos e Latoeira (2010) "Um estudo sobre as Cidades Criativas-Apresentação do diagnóstico aos estudos de caso: Lisboa, São Paulo e Barcelona", artigo produzido no âmbito do projecto de investigação Creatcity, no qual o presente estudo igualmente se insere.
} 
assinalados, os entrevistados referem ainda enquanto factor diferenciador o grande contraste existente entre duas formas de uso do bairro, dado que a vasta maioria dos utentes não são residentes.

Consultados sobre quais os factores passíveis de aumentar a vitalidade, a criatividade e a competitividade dos bairros, os inquiridos - com maior incidência de respostas acerca do Bairro Alto - apontaram uma série de necessidades de âmbito urbanístico, conforme descritas no quadro da Figura 17. contexto internacional em que diversas crises estruturais exacerbam a competitividade dos territórios, a grande vantagem competitiva dos "bairros culturais" reside acima de tudo na manutenção da vitalidade dos seus espaços públicos ${ }^{20}$.

Conforme vimos, a vitalidade do espaço público - aquilo que habitualmente entendemos por espaço público urbano, as ruas e praças, os espaços abertos exteriores - depende em grande parte da vitalidade e diversidade das actividades que ocorrem em determinados espaços interiores - os espaços

Figura 17 - Factores urbanísticos apontados enquanto passíveis de aumentar a vitalidade, a criatividade e a competitividade dos bairros

\begin{tabular}{|c|c|c|c|}
\hline & $\begin{array}{l}\text { BAIRRO } \\
\text { ALTO }\end{array}$ & $\begin{array}{c}\text { VILA } \\
\text { GRACIA }\end{array}$ & $\begin{array}{c}\text { VILA } \\
\text { MADALENA }\end{array}$ \\
\hline - Melhorar a infra-estrutura urbana (ex. estacionamento) & ○ & & $\bullet$ \\
\hline - Melhorar a mobilidade pedonal & ○ & & $\odot$ \\
\hline - Melhorar a cobertura de transportes públicos & & & ○ \\
\hline - Requalificar o espaço público & ○ & & $\bullet$ \\
\hline - Reabilitar e reconverter edificios degradados/devolutos & 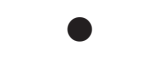 & & \\
\hline $\begin{array}{l}\text { - Melhorar o acesso ao mercado do arrendamento } \\
\text { (rendas demasiado elevadas) }\end{array}$ & ○ & - & \\
\hline $\begin{array}{l}\text { - Criar organismo/associação de interesses } \\
\text { (comerciais / culturais) locais }\end{array}$ & ○ & & \\
\hline $\begin{array}{l}\text { - Melhorar a qualidade de vida dos residentes } \\
\text { (ruído / mobilidade) }\end{array}$ & ○ & & ○ \\
\hline $\begin{array}{l}\text { - Compatibilizar as diferentes vivências do bairro } \\
\text { (moradores / comerciantes / consumidores) }\end{array}$ & ○ & & $\bullet$ \\
\hline - Melhorar a limpeza da via pública/ limpar os graffitis & - & & \\
\hline
\end{tabular}

\section{Conclusões}

Os casos de estudo analisados parecem confirmar o argumento de Gert-Jan Hospers (2003), quando este afirma que a criatividade não ocorre no vácuo, e que certos meios urbanos, ricos em sedimentos de história, são os lugares - os suportes físicos e sociais - por excelência onde a criatividade lança as suas raízes. Acrescentaríamos que, no actual privados de uso público - que com eles interagem. Os espaços privados de uso público, sejam eles restaurantes, bares, lojas de vestuário, escolas, oficinas, museus, ou academias de música - são extensões naturais dos espaços públicos exteriores, e contribuem decisivamente para o seu carácter e para a sua maior ou menor vitalidade.

Os bairros culturais serão tanto mais "criativos" quanto maior for a sua capacidade de atrair "actores

\footnotetext{
${ }^{20}$ A noção de competitividade territorial, tal como foi abordada no âmbito do projecto de investigação Creatcity, no qual o presente estudo se insere, implica "a capacidade de um espaço oferecer qualidade de vida e bem-estar aos seus cidadãos, permitindo-lhe assim sustentar, justamente, actividades e dinâmicas de desenvolvimento diferenciadoras face aos outros territórios".
} 
criativos" (indivíduos, instituições, actividades), que escolhem nele se fixar, residir, ou trabalhar, e o reconheçam enquanto lugar de encontro e trocas com os seus pares. A existência de um elevado número de actividades sociais e opcionais facilita os contactos interpessoais e interinstitucionais, e contribui para o aumento dessa atractibilidade. Por outro lado, a existência de um elevado número de actividades necessárias - dirigidas à comunidade local - é essencial ao bem-estar e à qualidade de vida dos residentes.

Os resultados da análise urbanística permitem concluir que, no que respeita à relação proporcional entre estas actividades, não há números de oiro ou proporções ideais: nos três bairros os tipos de actividades misturam-se em diferentes proporções, e a maior concentração de um ou de outro tipo de actividade gera apenas diferentes ambientes urbanos e diferentes vivências de bairro.

De acordo com as entrevistas realizadas, Vila Gracia, o bairro onde existe a maior concentração de actividades necessárias é um bairro acolhedor e agradável para os seus residentes, um bairro "pequeno" - como diz um dos entrevistados, apesar dos seus quase 100 hectares - onde se vive "como numa aldeia". Já no Bairro Alto e em Vila Madalena, onde predominam as actividades sociais (por definição com um grau de atractividade supralocal), verifica-se uma maior tensão entre os estilos de vida dos residentes e dos utentes do bairro, e os entrevistados sentem a necessidade de "compatibilizar as diferentes vivências do bairro" e gerar um maior envolvimento entre moradores, comerciantes e consumidores.

Em qualquer dos bairros, a elevada concentração de actividades opcionais (na sua maioria pertencentes ao sector "criativo") complementa o papel aglutinador das actividades sociais e atribui aos bairros uma marca de "criatividade urbana". A concentração destas actividades é precisamente referida pelos entrevistados enquanto um importante factor de criatividade.

No que toca às actividades urbanas em espaços privados de uso público, o mix de actividades produz diferentes formas de apropriação socioespacial, enquanto que concentração e diversidade surgem enquanto as qualidades essenciais à vitalidade dos bairros.

Quanto à área disponível de espaço público exterior relativamente ao espaço privado - uma relação de aproximadamente 1:3 no Bairro Alto, 1:2 em Vila Gracia, e 1:1,5 em Vila Madalena parece não haver, igualmente, uma receita ideal. No entanto, é de salientar que o Bairro Alto se situa já no limiar mínimo de quantidade de espaço público para tornar uma área urbana viável.

A morfologia do espaço público, por outro lado, surge como factor importante pois afecta directamente a forma como as pessoas dele se apropriam. Assim, apesar da sua malha densa, temos as inúmeras praças de Vila Gracia, autênticas salas de estar urbanas onde pessoas de várias idades e com motivações diversas se encontram informalmente a diferentes horas do dia. São espaços públicos aglutinadores sociais, que contribuem para reforçar o sentido de comunidade, ou - conforme afirmou um dos entrevistados - "um sentimento de identidade [de bairro] muito elevado".

Já o espaço público do Bairro Alto, dada a sua morfologia de ruas estreitas e a total ausência de praças, necessita cumprir duas funções simultâneas: espaço de estar e canal de circulação. Os encontros informais dão-se na rua - quer de dia (residentes e turistas), quer de noite (convívio à porta dos bares) - o que atribui às relações interpessoais um carácter mais transitório. Se as praças de Vila Gracia oferecem a oportunidade para um convívio mais "passivo" e inclusivo, aqui o convívio de rua (sobretudo à noite) é quase exclusivamente "activo" e fortemente dominado pela faixa etária dos jovens, algo que - na opinião de um entrevistado e residente - "é por vezes cansativo para quem cá mora".

A morfologia de Vila Madalena - uma malha ortogonal de longos quarteirões e ruas bastante largas (com duas ou três faixas de rodagem, estacionamento lateral e passeios amplos) - determina que o espaço público exterior seja partilhado, com algum conflito, entre peões e automóveis. A maior dispersão das actividades, como vimos, torna o uso do automóvel, ou de algum outro meio de transporte motorizado indispensável para muitas das deslocações intra-bairro. Além disso - conforme referido por um entrevistado - "o bairro é atravessado por muito tráfego de passagem", por vezes "em excesso". Os passeios mais amplos e o estacionamento paralelo ao passeio (que protege do tráfego automóvel), permitem no entanto a existência de esplanadas - locais privilegiados de convívio que contribuem muito para a vitalidade da rua - e oferecem diversos lugares informais para 
sentar e conviver com outros (como um muro, umas escadas de moradia, ou um recanto com bancos sob uma árvore).

Em qualquer dos três bairros - com maior intensidade em Vila Gracia e menor em Vila Madalena - o grande número de actividades urbanas origina naturalmente um grande número de fachadas activas e permeáveis. As fachadas activas e permeáveis, típicas dos espaços privados de uso público - com montras deixando ver luzes e decorações interiores, e portas abertas para a rua por onde se pode entrar e sair - são um factor importante para a pedonalidade do espaço público, pois contribuem para encurtar, subjectivamente, distâncias e também para enriquecer, sensorialmente, a experiência de andar na rua. A morfologia dos espaços públicos - ruas e praças delimitadas por fachadas de edifícios - é assim, nestes três bairros, dilatada muito para além das barreiras físicas que objectivamente os contém.

Ao nível da imagem, os três bairros têm em comum "uma mistura de elementos contemporâneos com elementos tradicionais", o que é visto enquanto um factor muito positivo. No caso de Vila Madalena, no entanto, conforme foi observado, "a possibilidade de substituição [permitida no plano director] de moradias unifamiliares por grandes prédios [alguns com cerca de 20 pisos] está a desvirtuar as características tradicionais" e o sentido de lugar do bairro. Quer em Vila Madalena, quer no Bairro Alto, a requalificação do espaço público foi apontada enquanto factor passível de melhorar a imagem e, consequentemente, aumentar a vitalidade do bairro. No Bairro Alto foi ainda apontada a necessidade de reabilitar os muitos edifícios degradados.

Resumindo as principais observações: 1) a concentração e a diversidade de actividades necessárias, sociais e opcionais são qualidades essenciais à vitalidade - e decorrente competitividade - das áreas urbanas; 2) os bairros estudados têm vita- lidade devido à presença intensiva daqueles três tipos de actividades; 3) é este mix de actividades, equilibrado por forma a servir residentes mas também orientado para o exterior, num ambiente urbano que se adapta à contemporaneidade sem perder as principais características tradicionais, que constitui um factor de atracção e fixação de usos e indivíduos criativos; 4) por outro lado, a morfologia do espaço público é importante, na medida em que afecta a forma como as pessoas dele se apropriam e, consequentemente, determina diferentes possibilidades de estilos de vida.

Algumas das reflexões actuais sobre a cidade criativa tendem a adoptar uma lógica funcionalista e economicista, que concebe a aglomeração de "indústrias" criativas com vista à criação de economias de escala, como se se tratasse da organização de um eficaz parque empresarial. Trata-se do mesmo racional sob o qual continuamos a promover um desenvolvimento urbano não sustentável baseado na suburbanização, no zonamento funcional, e na absoluta dependência do automóvel. $\mathrm{O}$ que o exemplo destes "bairros criativos" demonstra, no entanto, é que a competitividade de um território pode ser atingida de forma sustentável se ele for entendido enquanto um ecossistema complexo, que evolui e se adapta às novas condições de forma incremental, prosseguindo formas inovadoras sem no entanto perder a continuidade com a tradição e as formas do passado.

$\mathrm{O}$ presente estudo aborda apenas alguns aspectos essenciais, mas necessariamente parcelares, da criatividade do meio urbano. $\mathrm{O}$ aprofundamento do estudo destes bairros, nas suas múltiplas componentes, pode contribuir decisivamente não apenas para a sua própria continuidade enquanto territórios urbanos criativos, como também para o futuro desenvolvimento de cidades competitivas mas socialmente e culturalmente responsáveis. 


\section{Referências Bibliográficas}

ACS, Z. J. (2002), Innovation and the Growth of Cities. Cheltenham: Edward Elgar.

ALDOUS, Tony (1992), Urban Villages: A concept for creating mixed-use developments on a sustainable scale, London: Urban Villages Group.

BALULA, Luís (2008), "Dialéticas espaciais na cidade contemporânea - e o poder integrador do desenho urbano". Cidades, Comunidades e Territórios, n. $^{\circ} 15$.

BALULA, Luís (2000), “Um novo urbanismo para as áreas metropolitanas: tradição e a cidade do futuro". Revista Urbanismo, n. ${ }^{\circ} 4$.

BARNETT, Jonathan (2003), Redesigning Cities: Principles, Practice, Implementation. Chicago, IL: APA, Planners Press.

CARMONA, Matthew, Tim Heat, Taner Oc and Steve Tiesdell (2003), Public Places, Urban Spaces: The Dimensions of Urban Design. London, UK: Architectural Press.

CARR, Stephen, Mark Francis, Leanne G. Rivlin e Andrew M. Stone (1992), Public Space. Cambridge, MA: Cambridge University Press.

CHAPMAN, Thomas (2006), "Public Space." Encyclopedia of Human Geography. SAGE Publish.,

<http://www.sage-ereference.com.proxy.libraries.rutgers.edu/ humangeography/Article_n238.html>

CNU - Congress for the New Urbanism (2000), Charter of the New Urbanism. Leccese, Michael and Kathleen McCormick (Eds.), New York: McGraw-Hill.

COSTA, Pedro, Bruno Vasconcelos e Gustavo Sugahara (2007), "O meio urbano e a génese da criatividade nas actividades culturais". Comunicação no 13. Congresso APDR Recriar e Valorizar o Território. Açores, Portugal.

DEAR, Michael (2000), The Postmodern Urban Condition. Oxford: Blackwell.

DOMINGUES, Álvaro (2010), A Rua da Estrada. Porto: Dafne.

GARREAU, Joel (2001), "Face to face in the information age". Comunicação no Congresso City Edge 2: Center vs. Periphery. Melbourne, Austrália.

GEHL, Jan (1987), Life Between Buildings: Using Public Space. New York: Van Nostrand Reinhold, (versão original em dinamarquês, 1971).

Gilder, G. (2000), Telecosm: How Infinite Bandwidth Will Revolutionize Our World. New York: Free Press.

GLAESER, E. L. (2000) "The new economics of urban and regional growth". In G. L. Clark, M. P. Feldman and M. S. Gertler (Eds.), The Oxford Handbook of Economic Geography (p. 83-98). Oxford: Oxford University Press.
HAJER, Maarten and Arnold Reijndorp (2001), In Search of New Public Domain: Analysis and Strategy. Rotterdam: NAi Publishers.

HALL, P. (1998), Cities in Civilization. London: Phoenix.

HOSPERS, Gert-Jan (2003), "Creative cities: breeding places in the knowledge economy". Knowledge, Technology, \& Policy, 16(3), (pp. 143-62).

FLORIDA, Richard (2002), The Rise of the Creative Class: And How It's Transforming Work, Leisure, Community and Everyday Life. New York: Basic Books.

JACOBS, Allan B. (1993), Great Streets. Cambridge, MA: MIT Press.

JACOBS, Jane (1961), The Death and Life of Great American Cities. New York: Random House.

JACOBS, Jane (1969), The Economy of Cities. New York: Random House.

KELLY, K. (1998), New Rules for the New Economy: 10 Radical Strategies for a Connected World. New York: Viking.

LOZANO, Eduardo (1990), Community Design and the Culture of Cities. Cambridge, MA: Cambridge University Press.

LYNCH, Kevin (1981), A Theory of Good City Form. Cambridge, MA: MIT Press.

MITCHELL, William (1999), e-topia: 'Urban Life, Jim - But Not as We Know It'. Cambridge, MA: MIT Press.

MITCHELL, William (1999), City of Bits: Space, Place, and the Infobahn. Cambridge, MA: MIT Press.

OORT, F. G. van, (2003) Urban Growth and Innovation: Analysis of Spatially Bounded Externalities in the Netherlands. Aldershot: Ashgate.

QUIGLEY, J. M. (1998), "Urban diversity and economic growth". Journal of Economic Perspectives, 12(2), (pp. 127-38).

WALTERS, David and Linda Luise Brown (2005), Design First, Design-based Planning for Communities. Burlington, MA: Architectural Press.

WARREN, Stacy (2006), "Public Space." Encyclopedia of American Urban History. SAGE Publish.

$<$ http://www.sage-ereference.com.proxy.libraries.rutgers.edu/ urbanhistory/Article_n344.html>

WEBBER, Melvin (1964), “Order in diversity: community without propinquity." In Wingo, L. (ed.), Cities and Space: The Future Use of Urban Land, (pp. 23-153). Philadelphia: University of Pennsylvania Press,

WINNER, Langdon (2006), "Ascensão e queda de uma cidade tecnológica”. Análise Social, 181 (pp.1095-1103). 